\title{
Correction to: An exploration of Prevotella- rich microbiomes in HIV and men who have sex with men
}

Abigail J. S. Armstrong ${ }^{1,2}$, Michael Shaffer ${ }^{1,3}$, Nichole M. Nusbacher ${ }^{1}$, Christine Griesmer ${ }^{4}$, Suzanne Fiorillo ${ }^{4}$, Jennifer M. Schneider ${ }^{1}$, C. Preston Neff ${ }^{1}$, Sam X. Li ${ }^{1}$, Andrew P. Fontenot ${ }^{1}$, Thomas Campbell ${ }^{4}$, Brent E. Palmer ${ }^{1 *}$ and Catherine A. Lozupone ${ }^{1^{*}}$

\section{Correction to: Microbiome (2018) 6:198} https://doi.org/10.1186/s40168-018-0580-7

Following publication of the original article [1], the authors reported an error in Fig. 2. The original Fig. 2 has been incorrectly replaced with the Supplementary Fig. 2. The correct Fig. 2 is presented here.

\section{Author details}

${ }^{1}$ Department of Medicine, University of Colorado Denver, Anschutz Medical Campus, Aurora, CO, USA. '2Department of Immunology and Microbiology, University of Colorado Denver, Anschutz Medical Campus, Aurora, CO, USA. ${ }^{3}$ Computational Bioscience Program, University of Colorado Denver,

Anschutz Medical Campus, Aurora, CO, USA. ${ }^{4}$ Department of Surgery,

University of Colorado Denver, Anschutz Medical Campus, Aurora, CO, USA.

Published online: 06 April 2020

\section{Reference}

1. Armstrong AJS, Shaffer M, Nusbacher NM, Griesmer C, Fiorillo S, Schneider JM, Neff CP, Li SX, Fontenot AP, Campbell T, Palmer BE, Lozupone CA. An exploration of Prevotella-rich microbiomes in HIV and men who have sex with men. Microbiome. 2018;6:198.

\footnotetext{
The original article can be found online at https://doi.org/10.1186/s40168018-0580-7

* Correspondence: brent.palmer@ucdenver.edu;

catherine.lozupone@ucdenver.edu

'Department of Medicine, University of Colorado Denver, Anschutz Medical Campus, Aurora, CO, USA

Full list of author information is available at the end of the article
}

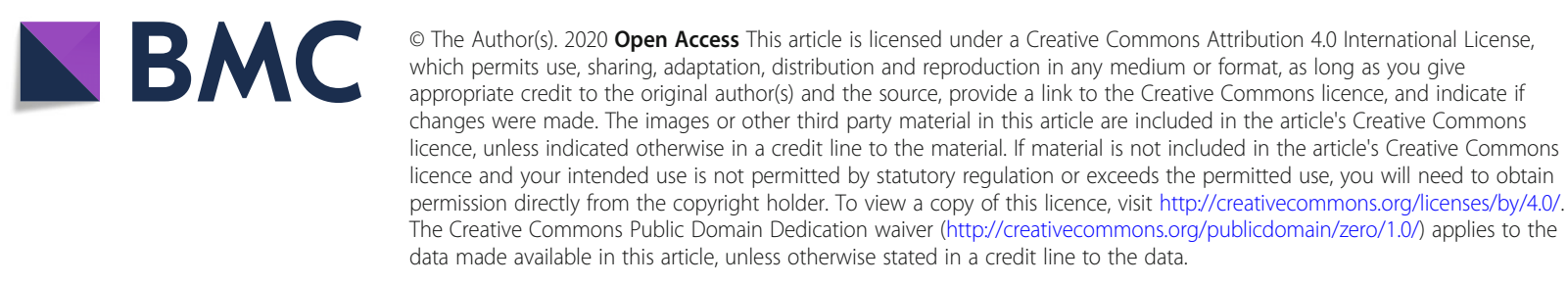




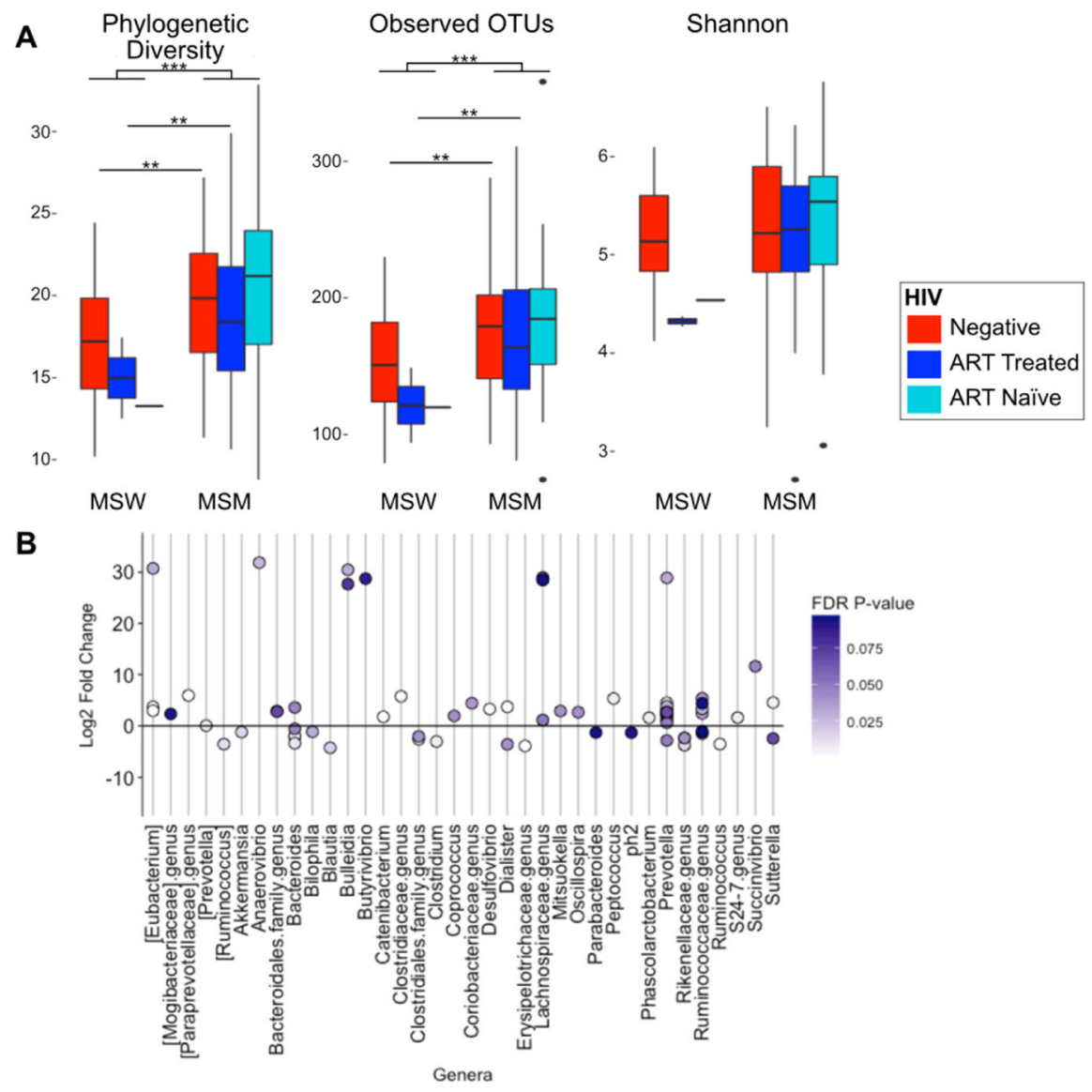

